\title{
Analysis and assessment of STATCOM's effectiveness in improving transient stability for power system
}

\author{
Le Ngoc Giang and Liu Kaipei \\ School of Electrical Engineering, Wuhan University \\ Luo-jia-shan Wuchang, Wuhan, Hubei Province, P.R.China, post code: 430072 \\ lengocgianglinh@gmail.com
}

\begin{abstract}
Many of papers refers to study of application for FACTS. Especially for using reactive compensators for $500 \mathrm{KV}$ power system in order to increase the static voltage stability margin and transient stability enhancement have considered. However the selection of suitable Var source (STATCOM or SVC) also need to be considered. The purpose of this paper is to solve the above problems in order to suggest a olution of the appropriate shunt compensator for a reality $500 K V$ power system. All the simulations for the above work have been carried out using MATLAB-SIMULINK environment.
\end{abstract}

Keywords: FACTS, SVC, STATCOM, Transient Stability of Power System

\section{Introduction}

Power systems components mainly consist of generators, transmission lines, transformers, switches, active or passive compensators and loads. Power system networks are complex systems that are nonlinear, non-stationary, prone to disturbances and faults.

In recent years, the electrical power system is continuously expanding in size and growing complexity all over the world. The electricity industry has undergone several changes due to privatization all over the world which has affected power system management and energy markets [1]. The power system which are heavily loaded, faulted and having shortage of reactive power are the main reason for voltage collapse [2]. As the voltage collapse problem is closely related to reactive power planning including the contingency analysis, as these should be considered for the secure operation of the power system [3]. During the outage conditions of some critical lines, the generators are capable of supplying limited reactive power even sometimes the supplied reactive power cannot be used to fulfill the requirement of the network because the location is far from the generator point. Further, more the real powers of the generators are reduced to supply the reactive power demand of the system. Hence, the reactive power compensators are used to maintain the voltage profile and there by improving the performances of the system [4].

Flexible Alternating Current Transmission Systems (FACTS) devices are becoming very popular for improving overall performance of power systems. FACTS devices are the solid state converters having capability of improving power transmission capacity, voltage profile, enhancing power system stability and security [5].

FACTS based equipment, provide proven technical solutions to voltage stability problems. Especially, due to the increasing need for fast response for power quality and voltage stability, the shunt dynamic Var compensators such as Static Var Compensators (SVC) and Static Synchronous Compensators (STATCOM) have become feasible alternatives to a fixed reactive source, and therefore have received intensive interests $[6,7]$. 
This paper focuses on the placement and selection of suitable Var source (STATCOM or SVC), for improving the voltage profile and reducing the real power losses for a reality $500 \mathrm{KV}$ power system. SVC and STATCOM is shunt FACTS devices which is designed to maintain the voltage profile in a power system under normal and contingency conditions. In practical power systems, all buses have different sensitivity to the power system security and stability. If SVC and STATCOM is allocated at more sensitive buses, it will effectively improve the voltage profiles and stability.

\section{Facts Devices}

SVC and STATCOM are the shunt devices of the FACTS family using power electronics to control power flow and improve transient stability on power grids $[8,9]$ to regulate voltage at its terminals by controlling the amount of reactive power injected into or absorbed from the power system. When system voltage is low, they generate reactive power (capacitive). When system voltage is high, it absorbs reactive power (inductive).

\section{Results and Analysis}

\subsection{Circuit Description}

Figure 1a shows the 3-Bus system used in the study. The power grid consists of two voltage sources $500 \mathrm{kV}$, frequency $60 \mathrm{~Hz}(1200$ MVA and 1500 MVA respectively ) connected by transmission lines: L1 $=90 \mathrm{~km}, \mathrm{~L} 2=65 \mathrm{~km}, \mathrm{~L} 3=75 \mathrm{~km}$. Load 1: Three-Phase Load P1=55 MW. Load 2: Three-Phase Load P2 $=45$ MW. Load 3: Three-Phase Load P3 $=800$ MW, Q3 = 200MVAr.
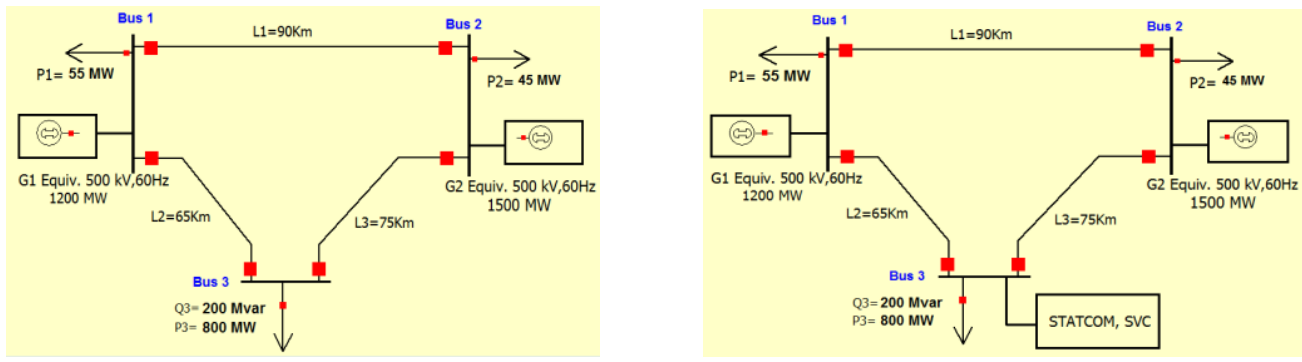

Figure 1. a.MODEL of Power Transmission System, b. MODEL of Power Transmission System with STATCOM, SVC

The load 3 the active power and the reactive power are 800MW and 200MVAR respectively. The percentages of load 3 are $25 \%, 50 \%, 75 \%$ and $100 \%$ in the operation. load 3 in $25 \%$ mode: $\mathrm{P} 325=200 \mathrm{MW}, \mathrm{Q} 325=50 \mathrm{MVAr}$. load 3 in $50 \%$ mode: $\mathrm{P} 350=400 \mathrm{MW}$, $\mathrm{Q} 350=100 \mathrm{MVAr}$. load 3 in 75\% mode: P375 $=600 \mathrm{MW}, \mathrm{Q} 375=150 \mathrm{MVAr}$. load 3 in 100\% mode: P3=800 MW, Q3 = 200MVAr.

Table 1. Voltages on the Bus of the Power System

\begin{tabular}{|c|c|c|c|c|c|c|c|c|c|c|c|}
\hline \multicolumn{4}{|c|}{ V1(pu) } & \multicolumn{4}{|c|}{ V2(pu) } & \multicolumn{4}{|c|}{ V3(pu) } \\
\hline $25 \%$ & $50 \%$ & $75 \%$ & $100 \%$ & $25 \%$ & $50 \%$ & $75 \%$ & $100 \%$ & $25 \%$ & $50 \%$ & $75 \%$ & $100 \%$ \\
\hline 1.065 & 1.021 & 0.9747 & 0.9289 & 1.064 & 1.021 & 0.975 & 0.9298 & 1.066 & 1.018 & 0.9692 & 0.9208 \\
\hline
\end{tabular}



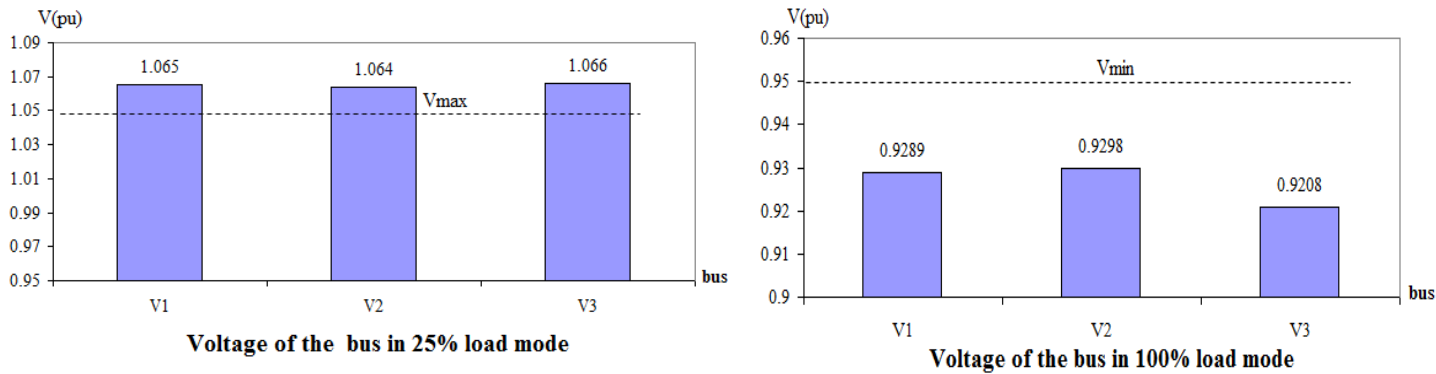

Figure 2. Voltage of the Bus in $25 \%$ and $100 \%$ Load Mode

When STATCOM and SVC are not operation, load 3 in $25 \%$ mode and $100 \%$ mode, V of the 3 bus are outside the specified limits [95\%, 105\%]. Especially in bus 3 the load voltage are $1.066 \mathrm{pu}$ and $0.9208 \mathrm{pu}$ in proportion to $25 \%$ and $100 \%$ load respectively.

To analyze and compare the efficiency of SVC and STATCOM for the enhancement of the power system stability, we consider SVC and STATCOM on the transmission line of power system, shown in Figure 1b.

The figure 1b shown above is model of the transmission line with STATCOM installed in bus B3, and has a rating of $+/-100 \mathrm{MVA}$. This STATCOM has a DC link nominal voltage of $40 \mathrm{kV}$ with an equivalent capacitance of $375 \mathrm{uF}$. On the AC side, its total equivalent impedance is $0.22 \mathrm{pu}$ on $100 \mathrm{MVA}$. This impedance represents the transformer leakage reactance and the phase reactor of the IGBT bridge of an actual PWM STATCOM.

\subsection{The Obtained Results}

The obtained results with and without the compensation of the reactive power were tabulated in Table 2, 3 and 4. When STATCOM and SVC are connected, the load Voltage has increased.

Table 2. Comparison of Voltage Regulation when SVC and STATCOM are Connected

\begin{tabular}{|c|c|c|c|c|c|c|c|c|c|c|c|c|}
\hline V & \multicolumn{4}{|c|}{ V1 } & \multicolumn{4}{|c|}{ V2 } & \multicolumn{4}{|c|}{ V3 } \\
\hline Mode & $25 \%$ & $50 \%$ & $75 \%$ & $100 \%$ & $25 \%$ & $50 \%$ & $75 \%$ & $100 \%$ & $25 \%$ & $50 \%$ & $75 \%$ & $100 \%$ \\
\hline Without & $\mathbf{1 . 0 6 5}$ & 1.021 & 097.47 & $\mathbf{0 . 9 2 8 9}$ & $\mathbf{1 . 0 6 4}$ & 1.021 & 0.975 & $\mathbf{0 . 9 2 9 8}$ & $\mathbf{1 . 0 6 6}$ & 1.018 & 0.9692 & $\mathbf{0 . 9 2 0 8}$ \\
\hline SVC & 1.031 & 1.011 & 0.9887 & 0.957 & 1.031 & 1.011 & 0.9898 & 0.9597 & $\mathbf{1 . 0 2 7}$ & 1.008 & 0.9863 & $\mathbf{0 . 9 5 3 6}$ \\
\hline Statcom & 1.021 & 1.001 & 0.9897 & 0.9589 & 1.021 & 1.001 & 0.9898 & 0.9591 & $\mathbf{1 . 0 2 2}$ & 1.003 & 0.9868 & $\mathbf{0 . 9 5 5}$ \\
\hline
\end{tabular}

Table 3. Comparison of Real Power Transfered when SVC and STATCOM are Connected

\begin{tabular}{|c|c|c|c|c|c|c|c|c|c|c|c|c|}
\hline P & \multicolumn{4}{|c|}{ P1 } & \multicolumn{4}{c|}{ P2 } & \multicolumn{3}{c|}{ P3 } \\
\hline Mode & $25 \%$ & $50 \%$ & $75 \%$ & $100 \%$ & $25 \%$ & $50 \%$ & $75 \%$ & $100 \%$ & $25 \%$ & $50 \%$ & $75 \%$ & $100 \%$ \\
\hline Without & 90.62 & 175.8 & 243.9 & 296.5 & 137 & 239.5 & 321 & 383.8 & 227.4 & 414.7 & 563.7 & 678.3 \\
\hline SVC & 84.05 & 172.2 & 252.5 & 318 & 127.1 & 234.6 & 332.4 & 411.5 & 211 & 406.2 & 583.7 & 727.5 \\
\hline Statcom & 84.31 & 172.2 & 252.6 & $319 . .3$ & 127.5 & 234.7 & 332.5 & 413.2 & 211.6 & 406.3 & 583.8 & 730.4 \\
\hline
\end{tabular}

Table 4. Comparison of Reactive Power Transfered when SVC and STATCOM are Connected

\begin{tabular}{|c|c|c|c|c|c|c|c|c|c|c|c|c|}
\hline Q & \multicolumn{4}{|c|}{ Q1 } & \multicolumn{4}{|c|}{ Q2 } & \multicolumn{3}{c|}{ Q3 } \\
\hline Mode & $25 \%$ & $50 \%$ & $75 \%$ & $100 \%$ & $25 \%$ & $50 \%$ & $75 \%$ & $100 \%$ & $25 \%$ & $50 \%$ & $75 \%$ & $100 \%$ \\
\hline Without & -114.1 & -77.87 & -47.05 & -18.97 & -140.6 & -96.68 & -56.76 & -21.32 & 56.85 & 103.7 & 140.9 & 169.6 \\
\hline SVC & -64.87 & -65.72 & -68.66 & -60.67 & -80.25 & -80.57 & -83.21 & -72.32 & 145.6 & 127.6 & 100.9 & 90.93 \\
\hline Statcom & -64.9 & -65.73 & -68.67 & -62.73 & -80.28 & -80.58 & -83.22 & -74.83 & 145.5 & 127.6 & 100.8 & 86.91 \\
\hline
\end{tabular}


Table 2, 3, 4 and Figure 3 show that, when SVC and STATCOM devices are entered in the operation, it has regulated the voltage in the allowed limit.

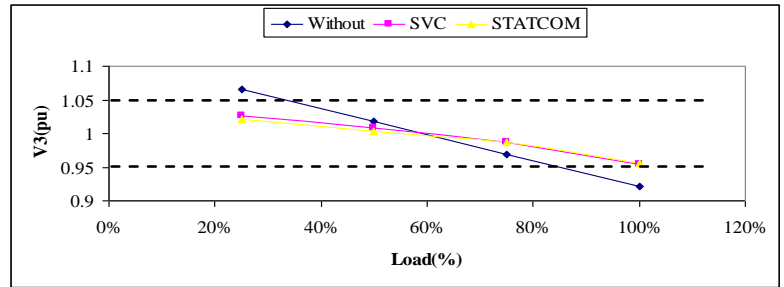

Figure 3. Voltage Regulation with and Without the Compensation

Figure 4 illustrate the Voltage and reactive power of 100\% load without the compensation.
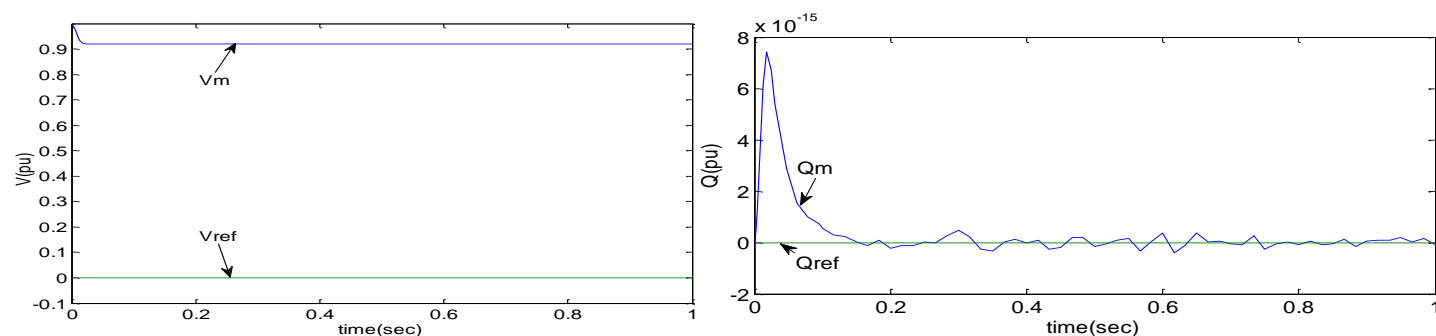

Figure 4. Voltage \& Reactive Power of $100 \%$ Load without the Compensation

Figure 5 and 6 show that the voltage regulation and reactive power generate or absorb when STATCOM \& SVC devices are connected in cases the percentage load are $25 \%$ and $100 \%$ respectively. Through which we see, voltage is controlled better when without STATCOM \& SVC.
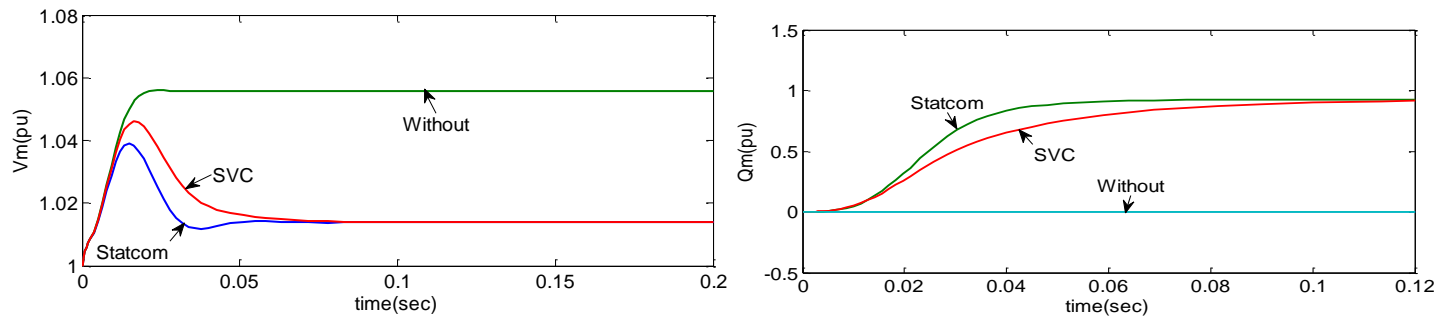

Figure 5. Voltage \& Reactive Power at Load Mode 25\% with and without Statcom \& SVC
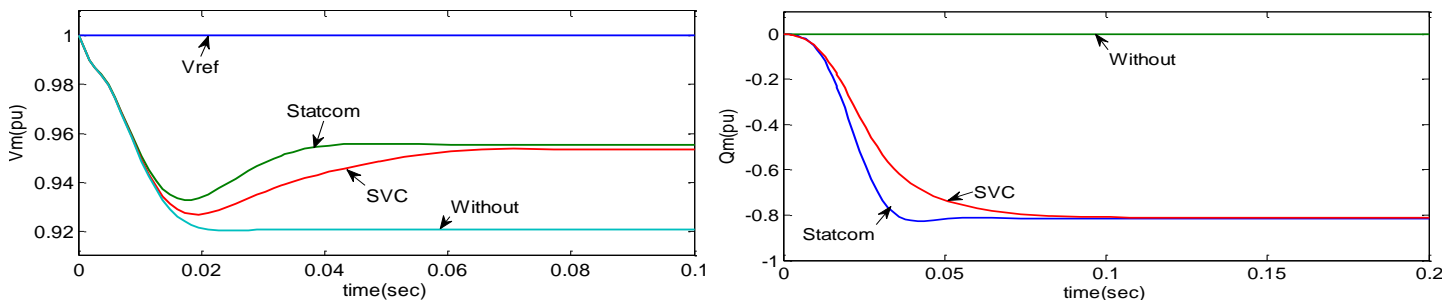

Figure 6. Voltage \& Reactive Power at Load Mode $100 \%$ with and Without Statcom\&SVC 


\subsection{The Fault Appears}

When the ground fault phase A appears, if without compensation the voltage will be $0.6371 \mathrm{pu}$. In contrast, if with STATCOM exists, the reactive power is - $0.6612 \mathrm{pu}$, at that time votage reached to $0.6632 \mathrm{pu}$. With SVC the reactive power is $-0.4303 \mathrm{pu}$, at that time votage reached to $0.6546 \mathrm{pu}$.

Figure 7 show the change of votage and reactive power when ground fault phase A appear with and without the compensation.
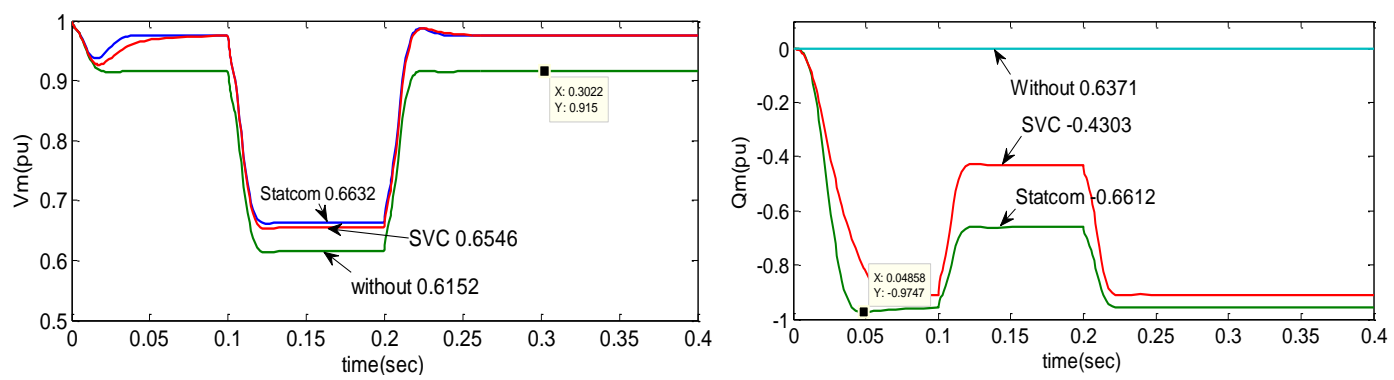

Figure 7. Voltage and Reactive Power when the Ground Fault Phase A appears, with and Without the Compensation

Applying the same analysis as aboves, when ground fault two phases A\&B appear. At that time, the effects of STATCOM will be better than these of SVC.

Figure 8 show that voltage and reactive power when ground fault two phases A, B appear with and without the compensation.
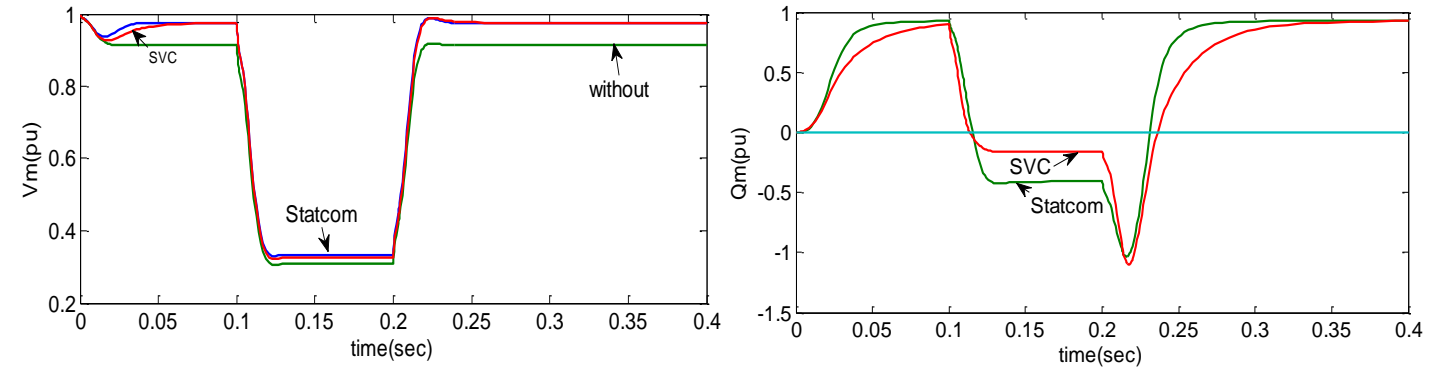

Figure 8. Voltage \& Reactive Power when the Ground Fault Phase A\&B appears, with and Without the Compensation

Figure 9 compares the effects between STATCOM and SVC under the condition when the three-phase of Breaker Fault appear in $t=0.1 \mathrm{~s}$ to $\mathrm{t}=0.2 \mathrm{~s}$.
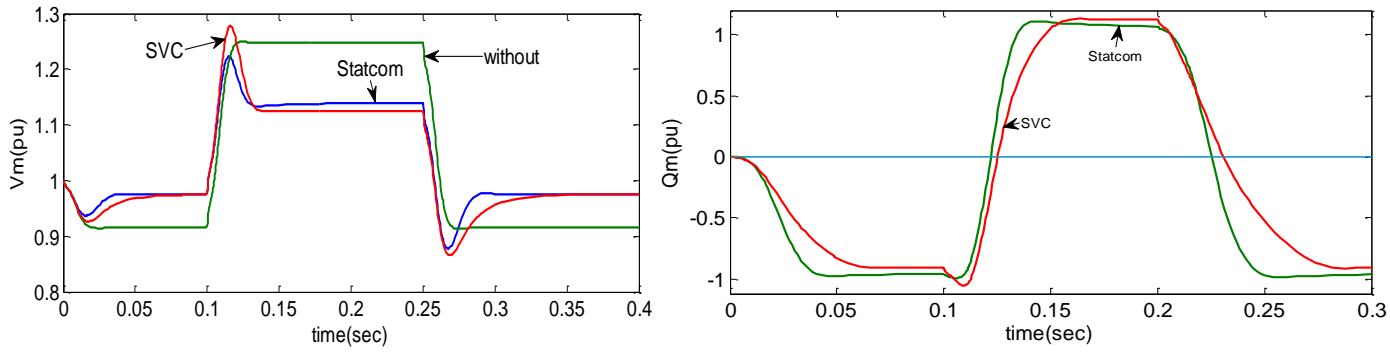

Figure 9. Voltage \& Reactive Power When Three-phase of Breaker Fault 
The results of Researched model indicated that STATCOM and SVC are very useful in improving the transient stability, Voltage profile \& power flow, as well as in providing the system a faster \& steadier state achievement. Simulation results show the effectiveness of SVC and STATCOM in controling the real and reactive power. Besides, STATCOM reacts faster and provides good effects to stabilize electric system, especially when faults appear.

\section{Identify Optimal Type of Reactive Power Generating Source in Fact of Power System}

Vietnam's $500 \mathrm{kV}$ grid system in 2015 was included in the survey of which the southern grid is considered to compensate reactive power because of large load demand which is dramatically increased. The two receiving/transmitting reactive power devices with equivalent size, which are included in the survey of stability in the domain time, are SVC and STATCOM.

In case of calculation with the capacity mobilized from the North to the South at the boundary value of $1550 \mathrm{MW}$, transmission capacity in $500 \mathrm{kV}$ grid connecting the Middle with the South is quite large. To evaluate the ability to improve the stability of the reactive power generating devices, the considered incident scenario is that incident is occurred on 3 permanent phases in 500kV lines from Di Ling to Tan Dinh, fault location is near Tan Dinh $500 \mathrm{kV}$ transformer station; main relay does not work, the preventive relays system send the turn-off delay signal with the time ranging from $0.7 \mathrm{sec}$ to $0.8 \mathrm{sec}$.

The results of analysis of phase angular oscillation of 1000MW generators in Tra Vinh show that after short-circuit breaking, breaking time is $0,7 \mathrm{sec}$; amplitude of phase angle of Tra Vinh generator in case of using reactive power compensation source created by SVC is greater than that in case of using STATCOM. With large amplitude if time of short-circuit elimination is increased, the system will be unstable.

Another survey with the same incident case but with short-circuit breaking time extending to $0.8 \mathrm{sec}$ is conducted. The Southern electrical system in case of reactive power compensation generated by SVC was unstable, while in case of that generated by STATCOM, the system still remains the stability.

Basing on the above calculation it can be concluded that in term of stability in the domain time, the reactive power compensation system generated by STATCOM will be controlled more quickly, flexibly and reliably than SVC.

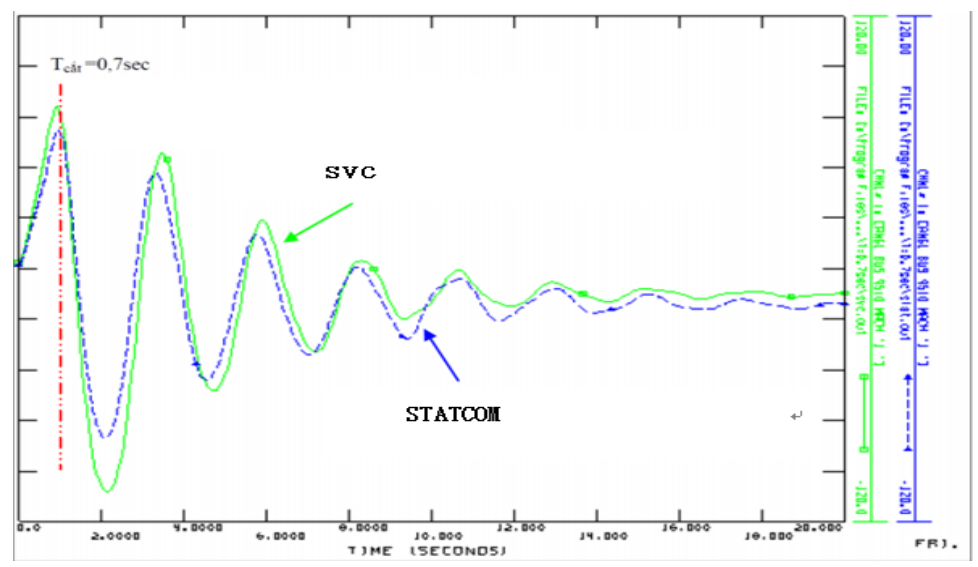

Figure 10. Phase Angle Oscillation of 1000MW Generating Set in Tra Vinh 


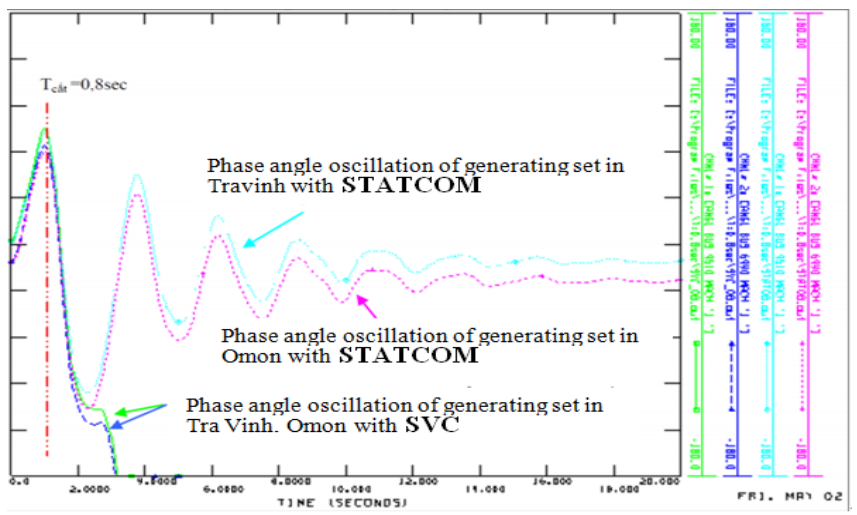

Figure 11. Phase Angle Oscillation of Generating Set in Tra Vinh, Omon

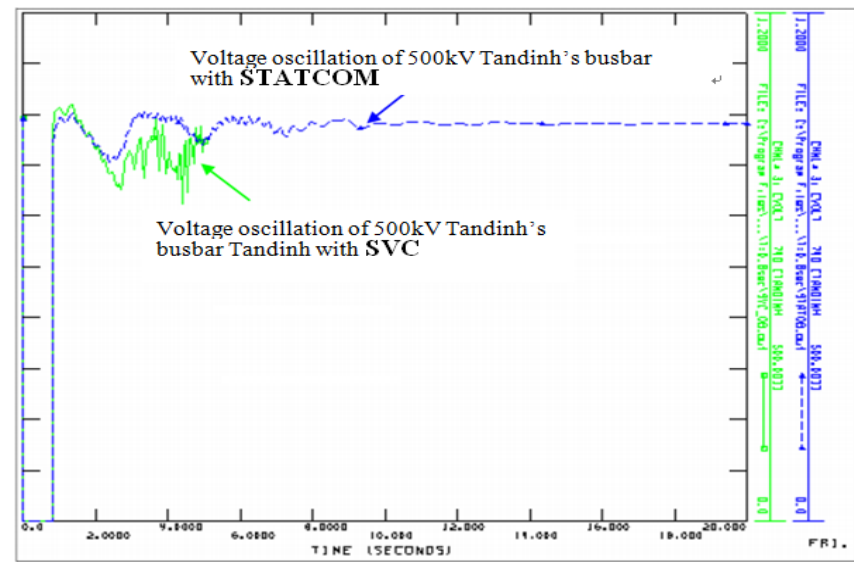

Figure 12. Voltage Oscillation of 500kV Tandinh's Bus Bar

\section{Conclusion}

In this study, the power system stability enhancement via STATCOM and SVC stabilizers is presented and discussed. An effort is made to assess voltage stability and security of multibus power system in presence of STATCOM and SVC. A comparative study on effectiveness of STATCOM and SVC in improvement of voltage stability and security has also been presented. STATCOM is found to be more effective than SVC to ensure voltage stability and security, at the same time, it is also capable to considerably reduce reactive power line loss. The results of this work are of certain practical significance and applicable value. Based on such calculation, For Vietnam's 500kV grid, power compensation by using STATCOM will improve operation stability better than using SVC.

\section{References}

[1] C. A.Canizares, "Applications of Optimization to Voltage Collapse Analysis", IEEEIPES Summer Meeting, San Diego, (1998) July 14.

[2] P. Kundur, L. Paserba, V. Ajjarapu, G. Anderson, A. Bose, C. A. Canizares, N. HatziargYfiou, D. Hill, A. Stankovic, C. Taylor, T. Van Cutsem and V. Vittal, "Definition and Classification of Power System Instability", IEEE Trans. On Power Systems, vol. 19, no. 2, (2004) May, pp. 1387-1401.

[3] Z. T. Faur, "Effects of FACTS Devices on Static Voltage Collapse Phenomena", M.S. dissertation, Dept. Elect. Eng., Univ. of Waterloo, (1996). 
[4] J. G. Singh, S. N. Singh and S. C. Srivastava, "An Approach for optimal Placement of Static Var Compensators Based on Reactive Power Spot Price”, IEEE Trans. On Power Systems, vol. 22, no. 4, (2007) November.

[5] I. A. Erinmez, "Static var compensators", CIGRE Working Group 38-01, Task Force No.2 on SVC, (1986).

[6] L. M. Tolbert and T. J. King, "Power electronics etrategy for transmission and distribution and for distributed energy", ORNL/TM- 2005/230, Oak Ridge National Laboratory, (2005) December.

[7] A. Scarfone, B. Oberlin, J. Di Luca Jr., D. Hanson, C. Horwill and M. Allen, "Dynamic performance studies for a \pm 150 Mvar STATCOM for Northeast utilities, Panel session on FACTS applications to improve power system dynamic performance", Proceedings of the IEEE PES T\&D Conference and Exposition, Dallas, Texas, (2003) September.

[8] A. Garg and S. Kumar Agarwal, "Voltage control and dynamic performance of power transmission system using STATCOM and it's comparison with SVC", International Journal of Advances in Engineering \& Technology, (2012) January.

[9] Y. Bai-jie, C. Qin, Y. Tie-jiang and Y. Hai-dong, "Research of STATCOM Impact on Wind Farm LVRT and Protection", TELKOMNIKA Indonesian Journal of Electrical Engineering, vol. 10, no. 8, (2012) December.

\section{Authors}

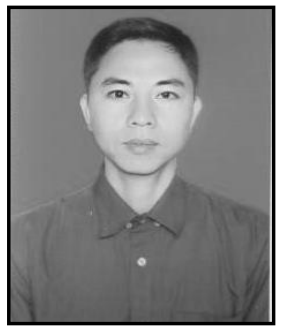

Le Ngoc Giang, he was born in Hanoi, Vietnam, on July 21, 1975. Currently, he is a Ph.D Student of Wuhan University, School of Electrical Engineering, His main research interests are power system control and power system stability analysis, smart grid demand response, building automation system, and renewable energy. lengocgianglinh@gmail.com

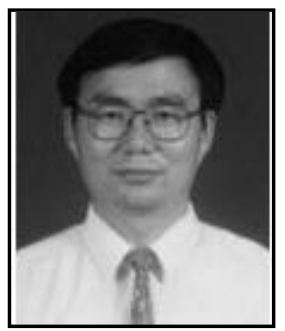

Liu Kaipei, he was born in Wuhan Province, China, in 1962. He graduated from Wuhan University in Computer Application Technology. Currently, he is a Professor and Vice Dean of School of Electrical Engineering, Wuhan University. His main research interests are Nonlinear control technolog, signal processing techniques in Power electronic systems, analysis and control of power quality, research on smart grid and the new energy. 